\title{
INCREASING AWARENESS FOR URBAN CULTURAL HERITAGE BASED ON 3D NARRATIVE SYSTEM
}

\author{
Benshuo Wang *; Gamze Z. Dane; Bauke de Vries \\ Information System Group, Eindhoven University of Technology, The Netherlands-(b.wang3, g.z.dane, b.d.vries) @ tue.nl
}

KEY WORDS: 3D narrative system; urban cultural heritage; tangible heritage; intangible heritage; awareness

\begin{abstract}
As UNESCO World Heritage Center defined, cultural heritage is legacy of physical artefacts and intangible attributes of a group or society that are inherited from past generations, maintained in the present and bestowed for the benefit of future generations. Recently, many advanced technologies such as virtual environment and narrative platform, have been applied in improving public awareness for cultural heritage to preserve historical sites. However, these tools have their own limitations. In order to have a powerful system, these technologies should be integrated. Therefore, this study describes the need and possible methodology for a new 3D narrative system. This system contains 2D maps, 3D city models and narrative format. Tourists and locals can use it as a guide to view the cultural heritages and view and insert their narratives during their visits. Another usage can be before going there and after visiting they can share their own experience and stories to others. On one hand, they can have a deeper understanding of cultural heritages, on the other hand, they can incorporate their cultural heritage narratives for others to explore these historical sites. In this way, more people will have an interest in these heritages, and the awareness for preserving them will be improved.
\end{abstract}

\section{INTRODUCTION}

As defined by UNESCO World Heritage Center (2005), cultural heritage $(\mathrm{CH})$ is the legacy of physical artefacts and intangible attributes of a group or society that are inherited from past generations, maintained in the present and bestowed for the benefit of future generations. These heritages define the values and identity of a city, one country or even to the whole world. They can portray the development of human beings, which could help the public to have a deep understanding of their history. However, internal and external barriers prevent cultural heritage based development; among them, lack of funds, insufficient knowledge about tourism economics, excessive presence of large investors, and ethnic or social discrimination can be named (Fatorić \& Seekamp, 2017; van der Borg \& Russo, 2005). These factors mentioned above can result in dismantlement or damage to historical buildings. The existed heritages could become obsolete areas, or can be misused and lose their original value. In such circumstances, cultural heritages fail to pass knowledge and history to the next generations. The public cannot visit them anymore or they will forget and lack awareness for the importance of these historical sites. Therefore, it is important to intrigue the public's awareness to preserve these cultural heritages.

One of the significant ways of increasing public awareness is to explain the value and past of the $\mathrm{CH}$ to the public. In the past, more static information based on written documents or paintings, are used to pass the history, memories and narrated stories to the next generations (Kaddu, 2015). However, it is difficult for the public to observe and understand all the static information when they are visiting the $\mathrm{CH}$, because people usually receive such information at $\mathrm{CH}$ site (Ashworth, 2011). This information shows on panels or in flyers are brief and curt, only introducing the highlights of the $\mathrm{CH}$. Travellers may want to know more details about these heritages, but the traditional media cannot support this which could have a negative impact on their $\mathrm{CH}$ awareness. Moreover, such static information is based on the authors' knowledge and hard to update with experiences and stories of the public who used or uses the $\mathrm{CH}$. Therefore, the public will get incomplete and limited information about heritages (Weiler \& Black, 2015). Thus, the public should also be involved in information generation which can increase their interest and therefore awareness for the $\mathrm{CH}$.

Many technologies, such as virtual environment, cultural mapping and story-telling, have been applied to help attract interests of the public in cultural heritage, but these technologies still have to be improved to gain more attention from people for urban cultural heritage. Cultural mapping is the use of research methods, tools, and techniques to identify, describe, portray, promote, and plan future use of particular regions or cities combined cultural assets and resources. One major weakness of cultural mapping method is that the related documents usually provided by the government. The official proofs define the cultural heritages, give a general overview of historical sites, but most people do not participate in. Therefore, the public cannot see the stories behind these heritages (Jeannotte, 2016). 3D digital models mainly focus on the visual, geometric, and textural characteristics of a single concrete object, while missing the integration of additional information such as historical overview, detailed description, and location (Koeva, Luleva, \& Maldjanski, 2017). Virtual reality can invite the public to explore the 3D historical model, but many people often find it is hard to navigate in the virtual environment (Bruder, Steinicke, \& Hinrichs, 2009; Riecke et al., 2010; Ruddle \& Lessels, 2009;MATTIAS, 2013 ;Guttentag, 2010;Tuck \& Kuksa,2009). What they see in the virtual world is rendered images and movies, however, such an approach may cause them to lose their interest to visit heritages personally. Augmented Reality (AR) enabled smartphone 
applications can be used to access personalized (and private), relevant and updated information at any time and place. However, the current technology still lacks interactivity, it can only show basic information on the screen. It cannot enable users to rate and comment immediately upon their visible surroundings (Yovcheva, Buhalis, \& Gatzidis, 2012; Lee \& Billinghurst, 2011).

To increase the awareness of cultural heritage, a new system should be developed. With heritage being both tangible and intangible, the challenge is to design solutions for generating a comprehensive picture of the studied assets, capturing and re-creating not only visual and structural information, but also stories and experiences together with their cultural, historical and social context and their evolution over time. This paper focuses on the development of a system that will integrate the advantages of digitalization with a function of story-telling and provide a platform where people can share their own stories with cultural heritage.

The paper is organized as follows. Section 2 provides an overview of current methods used in increasing awareness for urban cultural heritages. Section 3 presents the new architecture of 3D narrative system. Section 4 describes target cultural heritage-Strijp-S, and what category of data will be collected. Finally, section 5 presents the conclusions of this study, together with a roadmap for developing 3D narrative system.

\section{STATE-OF-ART}

Recently, urban cultural heritage is receiving more attention from the government and the public. Different methods have been implemented to improve the awareness of tourists and local citizens in order to protect the cultural heritage, however, they have little effect (Tou, To, To, \& Ac, 2008). Among them, the Information Communication Tools (ICT) has been created new opportunities for the awareness for cultural heritage (Argyropoulou, Dionyssopoulou, \& Miaoulis, 2006). Following we briefly discuss the most important methods found in the literature

\subsection{Virtual Reality}

VR (Virtual Reality) is a technology which could create a virtual environment (VE). In the $\mathrm{VE}$, people are surrounded by a three-dimensional computer-generated representation which is able to move around in the virtual world and people can see VE from different angles to reach into it, grab it, and reshape it (Haydar, Roussel, Maïdi, Otmane, \& Mallem, 2011). When exploring in the VE, in addition to visual sense, audio and kinetic senses can also be engaged (Mcbride, 2017). According to Thórisson \& Jonsdottir(2009), with the development of virtual reality technology, 3D virtual city model has been recognized as the most effective, interactive and dynamic option for an integrated environment, which can associate cultural with knowledge strongly. Virtual reality has many benefits for cultural heritages. On one hand, it can be used as knowledge carriers (Thórisson \& Jonsdottir, 2009), this technology can act as a teacher and impart knowledge to the public (Gruen, 2013; Wang, Huang, \& Wang, 2009). On the other hand, the public can use it as a virtual guide (Fassi et al., 2016), which could also increase the joy by immersing into the virtual environment. However, these successful projects only recreate the disappeared buildings in a virtual environment, they did not incorporate with the public's experience or presentation. They ignore feedbacks from citizens and tourists, the information flow is still one way (virtual reality to the public).

\subsection{Augmented Reality}

Augmented Reality is another different but effective technology used in urban cultural heritages. Olsson et al. (2013) argue that AR devices have the potential of replacing the traditional tourist guide and become the next generation personalized guide as personal service is gaining popularity across the service sector. In the meantime, tourist can use Augmented Reality to learn more detailed knowledge about historical sites regarding the destination (Fritz, Susperregui, \& Linaza, 2005; Yovcheva et al., 2012). In recent years, many companies have developed AR app used in a smartphone instead of traditional devices, such as head-mounted displays (Höllerer \& Feiner, 2004).. Moreover, AR provides people with a great opportunity to interact with a cultural heritage prior to the real trip (Lu \& Smith, 2008). Although AR has obvious advantages, it is still in an infant stage and is being further developed and explored in its capabilities, leading to a continual modification to define AR (Olsson, Kärkkäinen, Lagerstam, \& Ventä-Olkkonen, 2012);

\subsection{Story-telling}

The famous tangible cultural heritages of a city exist for dozens or hundreds of years. The stories behind these buildings are wonderful, which could attract the public's attention if these can be narrated in an effective and fabulous way. This idea was pioneered in the early $20^{\text {th }}$ century by the Scottish town planner Patrick Geddes (Jeannotte, 2016). In order to receive more stories, it demands public engage in this process, because citizens are "experts" about their communities in ways that go beyond official plans and established boundaries (Jeannotte, 2016). In the method of storytelling, users do not only create the meaning of the work by perceiving what author shows on the screen, but also participates in the development of the narrative, determines the storytelling process (Dvorko, 2015). The obvious advantage of this technology is a double way connection between human and computer and can give the audience the ability to discover and unveil the elements of a story while also and importantly entertaining them (Kwiatek \& Woolner, n.d.). Although this storytelling has many advantages in cultural heritages, so far it has not been developed a systematization of narrative theory structures in such a perspective, the traditional narrative structure is verbal, and be lack of the non-linearity (or multi-linearity) dimension of storytelling (Palombini, 2017). Moreover, some authors consider that interactivity and storytelling do not fit together because the users' actions interfere with the plot and the coherent development of the story is lost, which can be especially negative for highly structured processes such as learning (Paolini \& Blas, 2014).

\section{METHODOLOGY}

The awareness for cultural heritage is an important part of preserving them, and many different kinds of methodologies have been carried out to achieve this goal. These include virtual environment (Addison, 2000), 3D Geographical information, photogrammetry and narrative 
platform, and they indeed require good results to some extent. However, these technologies have their own limitations. The virtual tools can invite tourists to immerse in a virtual environment, but users can hardly interact with the digital city models. Even though travellers can handle their avatars in the virtual environment, they can just see static sites or follow prerecorded videos. As to storytelling, the public can share their experience and stories to the platform, but they cannot read them while visiting. In other words, stories and visualization are separated, it can obstruct visitors' understanding more deeply about historical sites.

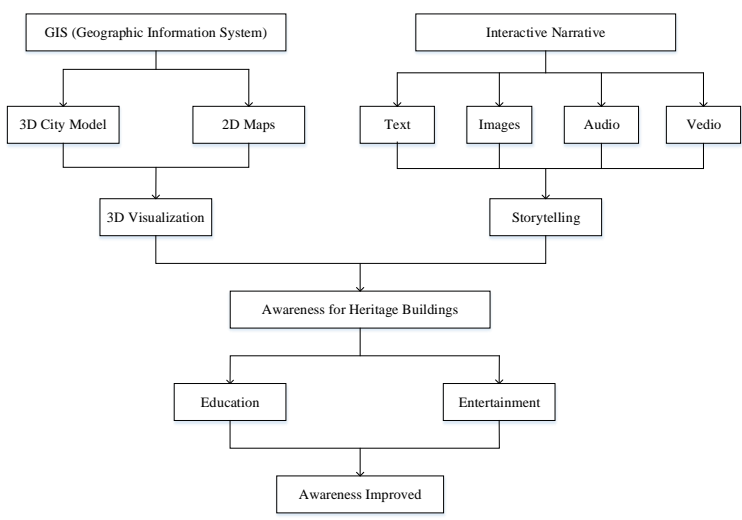

Figure 1 Research Framework

To overcome the disadvantages of existing technologies and to achieve the goal of increasing awareness for urban cultural heritages, we propose to combine 3D visualization and story-telling into a new 3D narrative system (Figure 1).

For this research, a common solution is to apply georeferenced data and digital maps to create a terrain model covered by aerial photos (El-Mekawy, Östman, \& Hijazi, 2012). Information about existing buildings is often available and buildings can be modelled as volumes with façade textures. In this case, public cadastral maps, elevation maps and associated aerial photographs of cultural heritages will be used to create a 3D city model. In the meantime, building heights of cultural construction captured from the AHN2 (Actueel Hoogtebestand Nederland) dataset, a current height data of the Netherlands, is used to extract the 2D map into a 3D model. Photos of the urban environment are attached to the facades to create a realistic impression.

Virtual reality has an advantage in creating environment which could allow the viewer to fully immerse themselves in what is happening around them. With virtual reality, users can move around and look around in every direction with glasses or helmet- VR software platforms such as Vizard or Unify will be applied for this purpose. With this technology, people can explore the environment through computer screens, their own smartphones or special tools, such as the helmet or glasses.

Interactive narrative is another important part of this project, the narratives are small "story-worlds" (Press, 2018). In the past, people usually pass their experiences from mouth to mouth. The cultural stories will disappear with the passing away of elderlies. Even though the buildings are preserved, their use might have changed and may not reflect the previous usages. Due to these reasons, a narrative system is needed to add personal stories from the visitors' collective memories and archives. The form of stories could be text, audio, picture and video. This system is a kind of platform, where people could share their comments and discuss their experience. All of the comments about this heritage will be showed on the website, people are free to read them. This platform will not be static but dynamic platform that can be extended with each added shared story.

The major challenge of this system is how to integrate virtual reality with cultural heritage narratives. These two parts belong to different file format, a bridging system should be created to combine them. CityGML(City Geography Markup Language), which is an open source is a good solution to solve this problem. CityGML is a new encoding standard, recommended by the Open Geospatial Consortium (OGC). This language is a common semantic information model for the representation of 3D urban objects that can be shared over different applications and it is also designed as an open data model and XML-based format for the storage and exchange of virtual 3D city models (Gröger, Kolbe, Nagel, \& Häfele, 2012). The architecture is described in more detail by using Level of Details (LoDs) CityGML(Mohd et al., 2017). As for the cultural heritage part, the information of narrative system could be also stored in XML format. The Application Domain Extension (ADE) concept supports two different methods which can be derived from existing CityGML using generalization concept (Mohd et al., 2017). The existing CityGML classes can be extended by additional attributes or relations (ADE-attributes). Another method is new class (ADE-class) can be defined and derived from existing CityGML classes using the generalization concept. Group et al (2010)created a new CityGML framework (GIRAPIM) for heritage and urban documentation. Figure 2A shows the general overview of this extension (Calle, Martinez, Delgado, Hurtado, \& Finat, 2010) The GIRAPIM extension includes three tasks: cultural heritage, pathology and intervention. The pathology and intervention parts mainly introduce accessibility problems and solutions for buildings but ignore the historical stories behind these architectures. Therefore, an updated extension is developed based on this project (see Figure 2B). Each module can be described as follows:

Cultural heritage: It is still the main module that imports CityGML building module.

History (new). This extension for the building module is introduced the history and changes for the building since it has been created.

Function (new). This module represents the functional changes of the building.

Narrative stories (new): This part includes the official and personal stories behind cultural buildings. In this extension, tourists could add their own stories for cultural heritages.

These new parts can be extracted from documents in different multimedia support (text, images, audio, videos). These documents could be stored as temporal files with CityGML (Morel \& Gesquière, 2014).

Extensible Address Language: The objective of $\mathrm{xAL}$ is to describe a common structure for International Addresses to enable any applications that wants to represent addressed in a common standard format. It is an open 
standard which could represent addresses of any country of culture, religion, language and geographic location (Extensible Address Language Standard Description Document for W3C DTD/Schema.).

Geography Markup Language: It is the XML grammar defined by the OGC to express geographical features. It has an ability to integrate all forms of geographic information.

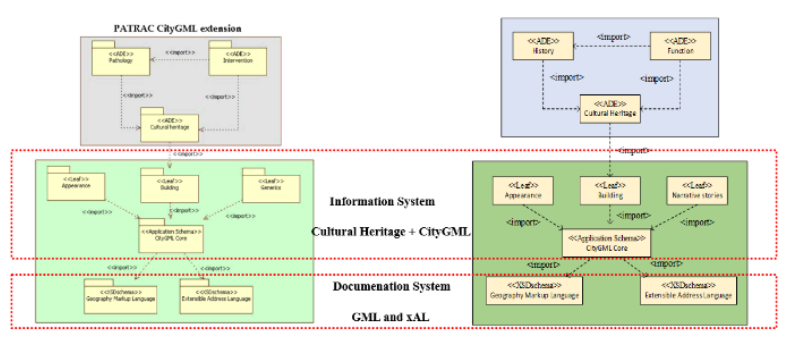

A B

Figure 2 A GIRAPIM CityGML extension (Arroyo, Biljecki, \& Diakit, 2017)

B New Cultural Heritage CityGML extension

The first stage of this system involves collecting the data to use for the visualization, which includes the geographic data and stories from the $\mathrm{CH}$ site. During this stage, data could be found on the websites and could be received from a face-to-face interview. On the second stage, all of the collected information should be compiled and analyzed. Separating the geographic and narrative construction is the main task at this stage. In the next step, two models should be created, 3D visualization model and narrative construction model. For 3D model, virtual reality is the first choice technology to build the virtual environment. As for the narrative construction, the stories about historical buildings should be chosen, which could intrigue the public awareness. Integrating narrative into 3D model is the final step.

Based on the elements of shape, style, function, history and changes of buildings, we create models of these constructions into virtual environment. In this environment, these cultural heritages can be recreated from the past. Due to weather changed, policy changed and wars, these buildings could be damaged, demolished or changed their functions. The public could have a great interested in the difference from past and now, they have a thirst to know what happened in the past and why these heritages have changed. By collecting these historical stories behind cultural constructions, and showing them on a (e.g. mobile) screen we aim to attract users' attention. In this way, the digital stories could be showed in the virtual environment and remind users interesting stories behind this heritage. Tourists and local citizens can use this system as a guide to explore a cultural heritage. It can not only show people basic information, but also interesting stories about this area. They can use it before or during their visits, through this system, they will learn more about cultural heritage places. When they explore in the virtual environment, if users are attracted by a different style construction, they can choose to explore stories behind the building or to read other tourists' comments, which could help them to keep interested in cultural heritages. With the enriched knowledge, they will have a deeper understanding of the heritages. Moreover, they may like to visit this place more than once and also invite other people to explore.

\section{STUDY AREA AND DATA COLLECTION}

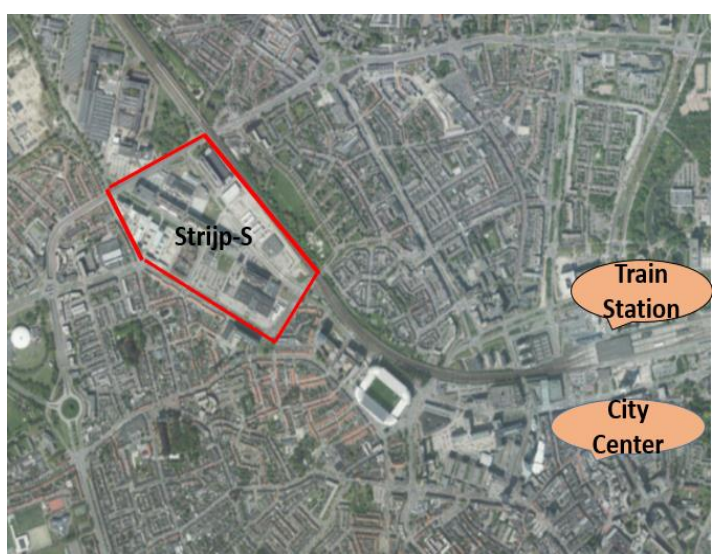

Figure 3 Map of Eindhoven

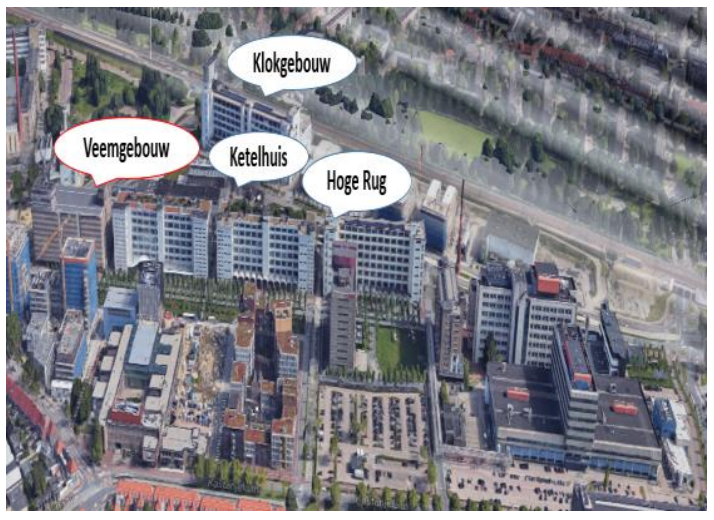

Figure 4 Historical Buildings of Strijp-S

Strijp-S, located in Eindhoven, the Netherlands (Figure 3 ) is an example of an infamous cultural scenery. The site belonged to electronics group Philips, due to the old industrial character, the area is considered as an industrial cultural heritage area. Strijp-S presents itself as the cultural heart of Eindhoven, which was a forbidden area, but now a mixed-use area that attracts many people with cultural events, festivals and other facilities. However, the area has developed and went through big changes in terms of usage (from only industrial usage to a mixed-use urban district). This cause the history of the area to be neglected and forgotten. In this project, four historical buildings will be considered (Figure 4).

The new 3D narrative system is a good method to solve this problem. To support the target area, two parts of data need to be collected: physical information and narrative stories. The physical information includes basic geographical maps and buildings condition. Geographical maps and part of building condition, such as terrain, base map and height could be download from AHN2 or BAG (Basic Registrations Addresses and Buildings), both of them are official geographical database of The Netherlands. Users can have a real experience only when the virtual environment can 
represent the real situation. Therefore, another part of buildings conditions, such as the outside look needs to be pictured on site.

Narrative stories is another important part of this system, besides the official stories, which provided by the government, it mainly can be divided into two sections: tourists and local citizens. For local citizens, Philips retired staff will be interviewed face to face, and their stories about Philips and Strijp-S area will be collected for the system. When the system is developed, tourists and local citizens could be invited to participate in the virtual environment. They can give feedback immediately during exploration or tourists can write down their feeling and stories after the first visit or the citizens can add other unknown information and stories about Strijp-S. All of these will be uploaded to the new system to enrich the database. In this way, more people visit cultural heritages on-site or off-site, the wider data basement can be informed and pass to future generations.

\section{CONCLUSION}

Cultural heritage is generally constructed, identified, interpreted and managed in line with certain values and meanings, and through selection processes linked to present and future political and economic visions and plans (Timothy, 2009; McDowell, 2008; Smith, 2006). Therefore, awareness is a significant component in protection of cultural heritage. People who live in the neighbourhood of a cultural heritage may harm it when they have not enough consciousness (UNESCO World Heritage Center, 2005). Thus, it is vital to enhance understanding and increase the public awareness for value and potentials of tangible and intangible cultural heritage.

Different kinds of advanced technologies have been developed to increase awareness for urban cultural heritages. Although they gain achievement to some extent, these tools cannot solve this problem perfectly. These methods either are hard to navigate in a virtual environment or highly dependent upon official

\section{REFERENCES}

Addison, A. C. (2000). Emerging trends in virtualheritage.IEEE Multimedia, 7(2), 22-25.

Argyropoulou, A., Dionyssopoulou, P., \& Miaoulis, G. (2006). Tourist Destination Marketing and Management Using Advanced ICTs Technologies, 365-369.

Arroyo, K., Biljecki, F., \& Diakit, A. (2017). TOWARDS AN INTEGRATION OF GIS AND BIM DATA: WHAT ARE THE GEOMETRIC AND TOPOLOGICAL ISSUES ?, IV(October), 26-27.

ASHWORTH, G. (2011). Preservation, Conservation and Heritage: Approaches to the Past in the Present through the Built Environment. Asian Anthropology, 10(1), 1-18.

Bruder, G., Steinicke, F., \& Hinrichs, K. H. (2009). Arch-explore: A natural user interface for immersive architectural walkthroughs. 3DUI - IEEE Symposium on $3 D$ User Interfaces 2009 - Proceedings, 75-82.

Calle, J., Martinez, R., Delgado, F. J., Hurtado, A., \& presentation and ignore the public engagement. They both separate the environment with stories behind cultural buildings. With heritage being both tangible and intangible, the challenge is to design solutions for generating a comprehensive picture of the studied assets, capturing and re-creating not only visual and structural information, but also stories and experiences together with their cultural, historical and social context and their evolution over time. The new 3D narrative system integrates advantages of digitalization with a function of story-telling and provides a platform where people can share their own stories with cultural heritage. In the meantime, a new cultural heritage extension with CityGML will be updated to interoperate the virtual environment and narrative system.

The 3D narrative system can intrigue people to visit the less famous cultural heritage sites. Visitors can be educated during the visit that the city has more to offer, giving an impulse to new economic activities and obsolete places. The 3D city model can be used as a basis for new urban design, and the system can be used to test publics' responses to these changes. The advantages and mistakes can be observed early. Compared with traditional methods, which only used for current building, not suitable for the features of vernacular heritage (Virtudes \& Almeida, 2016), the designers can correct potential drawbacks by using this new system. Public virtual urban design evaluation can save human and financial resources and avoid destruction of cultural heritage. The database of cultural heritage will be continuously enriched by visitors. Through the urban heritage awareness system, people from all over the world can consult the system to collect historical information for personal reasons or for research purposes.

The future work will complete the new 3D narrative system and the standards for this system. Related experiments will be carried out to test it.

Finat, J. (2010). Towards an integration of documentation, information and management systems in a common framework. International Archives of the Photogrammetry, Remote Sensing and Spatial Information Sciences - ISPRS Archives, 38(4W13).

Dvorko, N. (2015). DIGITAL STORYTELLING FOR CULTURAL HERITAGE PRESENTING The Diversity of Storytelling Forms, 68-70.

El-Mekawy, M., Östman, A., \& Hijazi, I. (2012). A Unified Building Model for 3D Urban GIS. ISPRS International Journal of Geo-Information, 1(3), 120 145.

Fassi, F., Mandelli, A., Teruggi, S., Rechichi, F., Fiorillo, F., \& Achille, C. (2016). Augmented Reality, Virtual Reality, and Computer Graphics, 9769, 139-157.

Fatorić, S., \& Seekamp, E. (2017). Securing the future of cultural heritage by identifying barriers to and strategizing solutions for preservation under changing climate conditions. Sustainability (Switzerland), 9(11).

Fritz, F., Susperregui, a, \& Linaza, M. (2005). Enhancing cultural tourism experiences with augmented 
reality technologies. The 6th International Symposium on Virtual Reality Archaeology and Cultural Heritage VAST, 20-21. Retrieved from

Gröger, G., Kolbe, T., Nagel, C., \& Häfele, K.-H. (2012). OGC City Geography Markup Language (CityGML) En-coding Standard. $O g c, 1-344$.

Group, M., Visualization, A., \& Belen, P. (2010). A 3D INFORMATION SYSTEM FOR SURVEYING CULTURAL HERITAGE ENVIRONMENTS, XXXVIII, 107-113.

Gruen, A. (2013). “Archaeologizing" Heritage?, (September).

Guttentag, D. A. (2010). Virtual reality: Applications and implications for tourism. Tourism Management, $31(5), 637-651$.

Haydar, M., Roussel, D., Maïdi, M., Otmane, S., \& Mallem, M. (2011). Virtual and augmented reality for cultural computing and heritage: A case study of virtual exploration of underwater archaeological sites (preprint). Virtual Reality, 15(4), 311-327.

Höllerer, T. H., \& Feiner, S. K. (2004). Mobile Augmented Reality. Understanding Augmented Reality, $1-39$.

Information, C., \& Technical, Q. (n.d.). Extensible Address Language ( xAL ) Standard Description Document for W3C DTD / Schema, 0 .

Jeannotte, M. S. (2016). Story-telling about place: Engaging citizens in cultural mapping. City, Culture and Society, 7(1), 35-41.

Kaddu, S. (2015). Collaboration in Digitising Cultural Heritage as a strategy to sustain access and sharing of cultural heritage information in Uganda. Library Theory and Research, 1-14.

Koeva, M., Luleva, M., \& Maldjanski, P. (2017). Integrating spherical panoramas and maps for visualization of cultural heritage objects using virtual reality technology. Sensors (Switzerland), 17(4), 1-15.

Kwiatek, K., \& Woolner, M. (n.d.). Embedding Interactive Storytelling within Still and Video Panoramas for Cultural Heritage Sites.

Lee, G. A., \& Billinghurst, M. (2011). CityViewAR : A Mobile Outdoor AR Application for City Visualization, $57-64$.

Lu, Y., \& Smith, S. (2008). Augmented reality ecommerce: how the technology benefits people's lives. Human-Computer Interaction.

MATTIAS, R. (2013). Development and Implementations of Virtual Reality for Decision-making in Urban Planning and Building Design.

Mcbride, M. (2017). Virtual Reality and Cultural Heritage: A Prospect for Archiving in 2017 Using a postmodern perspective to contextualise the role of archivists and other cultural heritage specialists in the, $0-75$.

McDowell, S. (2008). Heritage, Memory and Identity.
The Ashgate Research Companion to Heritage and Identity, (Ap), 37-53.

Mohd, Z. H., Ujang, U., Choon, T. L., Estate, R., Bahru, J., \& Universitet, D. T. (2017). HERITAGE HOUSE MAINTENANCE USING 3D CITY MODEL APPLICATION DOMAIN EXTENSION APPROACH, XLII(October), 14-15.

Morel, M., \& Gesquière, G. (2014). Managing temporal change of cities with CityGML.

Olsson, T., Kärkkäinen, T., Lagerstam, E., \& VentäOlkkonen, L. (2012). User evaluation of mobile augmented reality scenarios. Journal of Ambient Intelligence and Smart Environments, 4(1), 29-47.

Olsson, T., Lagerstam, E., Kärkkäinen, T., \& VäänänenVainio-Mattila, K. (2013). Expected user experience of mobile augmented reality services: A user study in the context of shopping centres. Personal and Ubiquitous Computing, 17(2), 287-304.

Palombini, A. (2017). Storytelling and telling history. Towards a grammar of narratives for Cultural Heritage dissemination in the Digital Era. Journal of Cultural Heritage, 24, 134-139.

Paolini, P., \& Blas, N. Di. (2014). Innovative Technologies in Urban Mapping, 10

Press, W. (2018). Review Reviewed Work ( s ): Possible Worlds, Artificial Intelligence, and Narrative Theory by Marie- Laure Ryan Review by: David Herman Source : SubStance, Vol . 23 , No . 2 , Issue 74 : Special Issue: Between Science \& Literature Published by: Univ, 23(2).

Riecke, B. E., Bodenheimer, B., McNamara, T. P., Williams, B., Peng, P., \& Feuereissen, D. (2010). Do we need to walk for effective virtual reality navigation? Physical rotations alone may suffice. Lecture Notes in Computer Science (Including Subseries Lecture Notes in Artificial Intelligence and Lecture Notes in Bioinformatics), 6222 LNAI, 234-247.

Ruddle, R. A., \& Lessels, S. (2009). The benefits of using a walking interface to navigate virtual environments. ACM Transactions on Computer-Human Interaction, 16(1), 1-18.

Smith, L. (2006). Uses of Heritage. Uses of Heritage, 1351.

Thórisson, K., \& Jonsdottir, G. (2009). Intelligent Virtual Agents, 9th International Working Conference, IVA 2009. Intelligent Virtual Agents (Vol. 5773).

Timothy, D. J. (2009). Book review: Ashworth, G.J., Graham, B. and Tunbridge, J.E. 2007: Pluralising pasts: heritage, identity and place in multicultural societies. London: Pluto Press. 236 pp. $£ 75$ cloth, $£ 19.99$ paper. ISBN: 9780745322865 cloth, 9780745322858 paper. Progress in Human Geography, 33(4), 560-561.

Tou, S., To, E. S. S., To, S. S., \& Ac, T. T. R. (2008) The Impact of Culture on Tourism.

Tuck, D., \& Kuksa, I. (n.d.). Virtual Heritage Tours : Developing Interactive Narrative-Based Environments 
for Historical Sites, 336-339.

UNESCO World Heritage Center. (2005). Basic Texts of the 1972 World Heritage Convention. Unesco, 1-234.

van der Borg, J., \& Russo, A. P. (2005). The impacts of culture on the Economic development of Cities. Retrieved from

Virtudes, A., \& Almeida, F. (2016). ICT Method for Evaluation of Heritage Buildings Conservation. Procedia Engineering, 161, 1910-1914.

Wang, F., Huang, X., \& Wang, Z. (2009). Research of autonomous active control for virtual human based on emotion-driven model. Lecture Notes in Computer
Science (Including Subseries Lecture Notes in Artificial Intelligence and Lecture Notes in Bioinformatics), 5940 LNCS, 177-189.

Weiler, B., \& Black, R. (2015). The changing face of the tour guide: One-way communicator to choreographer to co-creator of the tourist experience. Tourism Recreation Research, 40(3), 364-378.

Yovcheva, Z., Buhalis, D., \& Gatzidis, C. (2012) Overview of Smartphone Augmented Reality Applications for Tourism, 10(2), 63-66. 